\section{$\underset{\substack{\text { hommes } \\ \text { \& migrations }}}{ }$}

\section{Hommes \& migrations}

Revue française de référence sur les dynamiques

migratoires

$1284 \mid 2010$

Migrations et environnement

\title{
Kéthévane Davrichewy, La Mer noire
}

Paris, Sabine Wespieser, 2010, 214 pages, 19 euros

\section{Mustapha Harzoune}

\section{(2) OpenEdition}

\section{Journals}

\section{Édition électronique}

URL : http://journals.openedition.org/hommesmigrations/1282

DOI : 10.4000/hommesmigrations. 1282

ISSN : 2262-3353

\section{Éditeur}

Musée national de l'histoire de l'immigration

\section{Édition imprimée}

Date de publication : 1 mars 2010

Pagination : 206-207

ISSN : 1142-852X

\section{Référence électronique}

Mustapha Harzoune, « Kéthévane Davrichewy, La Mer noire », Hommes \& migrations [En ligne], 1284

2010, mis en ligne le 29 mai 2013, consulté le 24 septembre 2020. URL : http://

journals.openedition.org/hommesmigrations/1282 ; DOI : https://doi.org/10.4000/

hommesmigrations. 1282

Ce document a été généré automatiquement le 24 septembre 2020.

Tous droits réservés 


\title{
Kéthévane Davrichewy, La Mer noire
}

Paris, Sabine Wespieser, 2010, 214 pages, 19 euros

\author{
Mustapha Harzoune
}

\section{RÉFÉRENCE}

Kéthévane Davrichewy, La Mer noire, Paris, Sabine Wespieser, 2010, 214 pages, 19 euros

1 La Mer noire est un très beau récit, écrit avec retenue et délicatesse. Ce deuxième roman de Kéthévane Davrichewy inspiré de l'histoire familiale raconte un peu de la présence géorgienne en France et beaucoup du devenir français d'exilés géorgiens. La famille s'apprête à célébrer les quatre-vingt-dix ans de Tamouna. Le dîner d'anniversaire rassemblera pas moins de cinq générations. Entre les préparatifs de la journée, et plus tard entre les plats et les conversations, Tamouna se souvient. Le présent se mêle au passé, soupèse ce qu'il doit aux années et aux générations, s'émancipe grâce aux plus jeunes, au prix aussi de la vieillesse et de la mort.

2 La vieille femme est lucide, les poumons privés d'oxygène, son quotidien ne se réduit plus qu'à son appartement et à cette fenêtre ouverte sur la rue et sur la cour d'une école. Plusieurs fois par semaine Mohamed, le vieil immigré marocain qui travaille à l'épicerie, lui fait les courses et un peu de ménage. "Elle l'écoute, elle le force parfois à dire les mauvais traitements qu'il a subis au palais. Il le dit par bribes avec réticence. Elle se reproche ensuite son insistance. Elle-même ne parle jamais des raisons de son exil." Tsiala, sa petite-fille voudrait aussi que sa grand-mère lui raconte son histoire, elle la violente un peu comme elle-même le fait avec Mohamed.

3 Tamouna laisse remonter à la surface les souvenirs d'une vie longue et troublée. Au centre de ses réminiscences, il y a le visage de Tamaz, ce tendre amour né sur les bords de la mer Noire, toujours présent, aussi fort qu'au premier jour, malgré des destins séparés. Tamaz sera-t-il de la soirée ? Elle le souhaite et le craint dans le même mouvement. L'amour est comme un fil ténu qui court entre les femmes de cette histoire. Les plus jeunes demandent à leurs aînées si elles ont connu d'autres hommes que leur mari, si elles se sont mariées par choix ou par obligation. Tamouna s'est posée 
la question à propos de ses grands-parents restés en Géorgie, plus tard, elle a interrogé Dédia sa mère, et aujourd'hui c'est Tsiala qui le lui demande.

4 Les Géorgiens en France! En voilà une histoire, peu ou pas connue, noyée dans les différentes vagues d'immigration qui, depuis 1918, s'installèrent dans l'Hexagone. Ces Géorgiens sont devenus des Français d'origine géorgienne, sans faire de bruit, ou presque. Et pour cause :pour les premiers arrivés, il n'était pas question d'abuser de l'hospitalité française, certains qu'ils étaient de rentrer au pays au plus vite. Rien à voir avec les Juifs de Russie pour qui "le retour est inenvisageable, ils ont l'intention de construire une nouvelle vie ici. Nos exils et nos communautés ne se ressemblent pas. Tandis que nous attendons le retour, ils s'installent", dit Tamouna. La nostalgie n'avait pas sa place à écouter Kéthévane Davrichewy, sûre, qu'un jour ou l'autre, on retournerait au pays.

5 Mais voilà la révolution russe et le Géorgien Joseph Vissarionovitch Djougachvili, dit Staline, en décidèrent autrement. Les exilés se sont fondus dans la communauté nationale, entretenant le souvenir du pays quitté.

6 Tamouna porte, pour quelque temps encore, la mémoire de cette famille. C'est elle qui tisse le lien entre les générations, entre la Géorgie et cette terre d'accueil qui fut un temps terre d'exil. Son corps fatigué rassemble le temps et l'espace, l'histoire d'une famille française à la fois singulière, dans une France terre de diversité, et banale, tant le chaudron républicain finit par faire ressembler chacun à son voisin de palier.

7 L'écriture de Kéthévane Davrichewy est brève, économe, sans "effusions", à l'image de Tamouna. Le "je", celui de Tamouna, restitue le passé, tandis que le présent est porté par un narrateur extérieur, comme si, déjà, il fallait laisser la place à d'autres. Si comme le déclarait l'auteure lors d'une émission diffusée sur France Culture, son récit n'est nullement nostalgique, il faut alors évacuer cette impression laissée par le roman ou projetée par le lecteur. Ce ne sont pas alors des regrets qu'inspirent la lointaine Géorgie, l'amour contrarié ou le temps qui passe. Le pays comme l'amour demeurent bien vivants dans le cœur et dans les souvenirs de Tamouna. Quant au temps, elle ne souhaite qu'une chose: "Mourir dans son sommeil, c'est ce qu'elle préférerait. Mais tenir jusqu'à l'été. Sentir encore sa chaleur, son parfum sur la peau." 